\title{
Assessing Safety of Direct Thrombin Inhibitors, Direct Factor Xa Inhibitors and Vitamin K Antagonists in Patients with Atrial Fibrillation: A Nation-Wide Propensity Score Matched Cohort from Sweden
}

This article was published in the following Dove Press journal: Clinical Epidemiology

\author{
Marie Linder (D) \\ Anastasia Iliadou Nyman ${ }^{2,3}$ \\ Helle Kieler' \\ Bengt Danielsson (iD ${ }^{2}$ \\ Natalia Borg (iD) ${ }^{2}$ \\ Marcus Gry ${ }^{2}$ \\ Julius Collin (iD ${ }^{2}$ \\ 'Centre for Pharmacoepidemiology, \\ Karolinska Institutet, T2, Karolinska \\ University Hospital, Stockholm, Sweden; \\ ${ }^{2}$ The National Board of Health and \\ Welfare, Stockholm, Sweden; \\ ${ }^{3}$ Department of Medical Epidemiology \\ and Biostatistics, Karolinska Institutet, \\ Stockholm, Sweden
}

Purpose: To evaluate associations between first-time use of direct oral anticoagulants or vitamin $\mathrm{K}$ antagonists and bleeding risk or mortality in the elderly with atrial fibrillation in a real-world setting in Sweden.

Patients and Methods: The study population comprises first-time users, above age 60, of dabigatran, apixaban, rivaroxaban, or warfarin, with first atrial fibrillation occurrence within 6 months before dispensing (2012-2016). Outcomes were gastrointestinal, any, or intracranial bleeding, and mortality. Exposure started at first dispensing of a study drug. Follow-up continued until outcome, end of drug supply, dispensing of another study drug, death or end of study (December 2016). We conducted a propensity score matched, nationwide register-based cohort study including three treatment groups: direct thrombin inhibitors, direct factor $\mathrm{Xa}$ inhibitors and vitamin $\mathrm{K}$ antagonists, each compared to the other two, focusing on subgroups of age and sex. Cox proportional hazard models adjusted for CHA2DS2VASc and HAS-BLED scores provided hazard ratios with $95 \%$ confidence intervals.

Results: The matched study populations consisted of 7,264 patients for the direct thrombin inhibitors vs vitamin $\mathrm{K}$ antagonists comparison, 12,566 patients for the direct factor Xa inhibitors vs vitamin $\mathrm{K}$ antagonists comparison and 6,606 patients for the direct factor Xa inhibitors vs direct thrombin inhibitors comparison, in total 26,436 patients. Numerically high, but imprecise, hazard ratios for gastrointestinal bleeding were observed for women aged $75-80,80-85$, or above 85 years, eg $6.00(1.02,113.47)$ for direct thrombin inhibitors vs vitamin $\mathrm{K}$ antagonists. For both sexes, numerically high hazard ratios for any bleeding were observed in ages $80-85$, or above 85 years, eg 2.90 $(1.01,10.41)$ for direct thrombin inhibitors vs vitamin $\mathrm{K}$ antagonists. Numerically high HRs for intracranial bleeding were observed for women aged 75-80 or 80-85 years, eg $2.70(0.65,18.19)$ for direct factor $\mathrm{Xa}$ inhibitors vs vitamin $\mathrm{K}$ antagonists. Excess mortality was observed in both sexes, across age groups, for naive and experienced anticoagulant users.

Conclusion: The observed increased gastrointestinal bleeding risk in first-time users of direct thrombin inhibitors or direct factor Xa inhibitors is consistent with previous studies. The possible risk of excess mortality merits further studies.

Keywords: anticoagulants, arrhythmia, epidemiology, safety
Centre for Pharmacoepidemiology,

Karolinska Institutet, T2, Karolinska

University Hospital, Stockholm I7I 76,

Sweden

Tel +46 8-5I7 79I 75

Email marie.linder@ki.se 


\section{Introduction}

Atrial fibrillation (AF) is a potent risk factor for stroke and an important cause of mortality. The prevalence of AF in Sweden was $2.9 \%$ in 2010 for ages 20 years and above, rising with age, up to $14.3 \%$ by age 84 years. ${ }^{1}$ Lindberg et al found the prevalence of $\mathrm{AF}$ to be $4.9 \%$ among a cohort aged 60 years or older. ${ }^{2}$

Earlier, warfarin was the most common treatment in patients with AF for the prevention of stroke, but nowadays the direct oral anticoagulants (DOACs) have gained use. The direct thrombin inhibitor (DTI) dabigatran has been available for stroke prevention in AF in Sweden since December 2011. The direct factor Xa inhibitors (Xabans) rivaroxaban and apixaban have been available since September 2008 and May 2012, respectively.

There are several benefits with DOACs such as its simple fixed-dose regimen, no routine laboratory monitoring due to reduced variability in the anticoagulation effect, and potentially fewer drug interactions. ${ }^{3-5}$ However, there are reports on major bleedings, more specifically gastrointestinal bleedings associated with DOACs, especially in elderly users and users with renal impairment. ${ }^{6-9}$ Further, real-world data regarding bleeding risks have been conflicting. ${ }^{7,10-12}$

The randomized evaluation of long-term anticoagulation therapy (RE-LY) study found that compared to warfarin, dabigatran $150 \mathrm{mg}$ was superior with respect to stroke and systemic embolism and similar with respect to major bleedings, and that dabigatran $110 \mathrm{mg}$ was similar with respect to stroke and systemic embolism and superior with respect to major bleedings. ${ }^{13}$ In the Apixaban for Reduction in Stroke and Other Thromboembolic Events in Atrial Fibrillation (ARISTOTLE) trial, it was found that apixaban was superior to warfarin with respect to stroke, systemic embolism, bleedings, and mortality. ${ }^{14}$ In the Rivaroxaban Once Daily Oral Direct Factor Xa Inhibition Compared with Vitamin $\mathrm{K}$ Antagonism for Prevention of Stroke and Embolism Trial in Atrial Fibrillation (ROCKET AF), it was demonstrated that rivaroxaban was noninferior to warfarin for stroke and systemic embolism, and no significant difference of major bleedings was found. ${ }^{15}$

The aim of the current study was to evaluate the association between first-time use of DOACs or vitamin $\mathrm{K}$ antagonists (VKAs) and the risk for bleedings and allcause mortality in elderly patients diagnosed with $\mathrm{AF}$, in a real-world clinical setting in Sweden.

\section{Patients and Methods}

\section{Data Sources}

The study population was derived through linkage of national population-based registers, enabled via the unique identification number assigned to each citizen. ${ }^{16}$ In 2016 the Swedish population comprised almost 10 million people.

The Swedish patient register (NPR) started in 1964. The inpatient part of the register gained full coverage from 1987 and information from outpatients was included starting from 2001. The validity of the register is high with positive predictive values generally $85-95 \%$ for the majority of diagnoses. ${ }^{17}$ From NPR (using inpatient data from 1997 and outpatient data from 2001) information about AF, bleeding outcomes, comorbidities, CHA2DS2VASc, and HASBLED scores (Supplemental Table 1) were retrieved using the International Classification of Diseases $10^{\text {th }}$ revision (ICD-10). Hospitalization days and the number of visits to specialized care were also obtained from NPR.

The Swedish prescribed drug register (PDR) started in July 2005 and contains all community pharmacy dispensed medicines recorded by the Anatomic Therapeutic Chemical Classification system (ATC). ${ }^{18}$ Using PDR we retrieved dispensing data on dabigatran (ATC: B01AE07), apixaban (ATC: B01AF02), rivaroxaban (ATC: B01AF01), warfarin (ATC: B01AA03), other anticoagulants and other drugs (Supplemental Table 2 and 3). We also retrieved data on dispensing county, private clinic prescriber, and urban area living from PDR. The Swedish cancer register provided information on any cancer (ICDO2/3 codes: C00-D48) from 1997 onwards. From the Swedish register of care and social services for the elderly and for persons with impairments, we retrieved information on certain municipal services. Level of education was retrieved from the Swedish education register and the date of death was retrieved from the Swedish cause of death register.

\section{Study Design and Population}

We conducted a propensity score matched, nationwide register-based cohort study in Sweden with data covering 1 December 1997 to 31 December 2016. Essentially, in Sweden 2012-2016, VKAs equal warfarin, DTIs equal dabigatran etexilate and Xabans equal rivaroxaban and apixaban. The study population comprised first-time users, above the age of 60 , of DTIs, Xabans, or VKAs, with the first-time occurrence of AF (ICD-10: I48) within 6 months before dispensing date (January 2012 - November 2016). 
Exclusion criteria were: hip or knee surgery (surgical codes $\mathrm{NF}$ and NG) within 5 weeks before dispensing, or any of the following conditions: stroke (I61-I64), deep vein thrombosis (I80.2) pulmonary embolism (I26), bleedings (Supplemental Table 4), inherited or acquired bleeding disorders (D564, D58, D66, D67, D680, D681, D682, D684, D685), any cancer within 6 months before dispensing, or hospitalized at dispensing.

\section{Exposure}

Start of exposure was the date of the first dispensing of either dabigatran, apixaban, rivaroxaban, or warfarin (index date). Patients were followed until the occurrence of an outcome, end of the supply of the index drug, dispensing of another study drug, death or end of study (31 December 2016). Duration of each dispensing was calculated as the dispensing date plus the number of days supplied according to the WHO defined daily dose. ${ }^{19}$ For a subsequent dispensing to count as continuous supply, a maximum gap of 75 days, capturing $90 \%$ of all refills, was allowed between two dispensing dates, overlapping duration was cut short.

\section{Outcomes}

The primary outcome was gastrointestinal bleeding. Secondary outcomes were intracranial bleeding, any bleeding (a composite of other bleeding, gastrointestinal bleeding and intracranial bleeding) and all-cause mortality (Supplemental Table 4).

\section{Statistical Analysis}

The main analysis was subgrouped by age and sex simultaneously. We also performed analyses for one-way subgroupings: sex, age or previous use of other anticoagulants (experienced: within 2 years, naïve: more than 2 years). Baseline characteristics were reported by means and standard deviations for quantitative characteristics and with frequencies and proportions for qualitative characteristics.

We included three treatment groups; DTIs, Xabans and VKAs. Each group was compared to the other two, resulting in DTIs vs VKAs, Xabans vs VKAs and Xabans vs DTIs. In order to assure balanced characteristics, separate propensity score (PS) 1:1 matching was employed for each of the three comparisons before analyzing. Patients were matched selected randomly with no replacement using PS matching based on a greedy matching algorithm with 0.09 as the largest distance between matches. ${ }^{20}$ PS was obtained from logistic regression models with the following baseline information (recorded ever before dispensing date) included: age (60-74, 75-79, 80-84 and 85+ years), dispensing county (21 counties), urban city living (yes/no), education (9-year compulsory school, high school, tertiary education and missing), dispensing period (quarters 2012-2016), private clinic (yes/no), number of hospitalization days $(1-3,4-10,>10)$, number of visits in specialized care $(1-3,4-10,>10)$, granted hours of municipal services $(<45,45-90,>90)$, indicators of vascular disease, congestive heart failure, transient ischemic attack, embolism, diabetes, hypertension, alcohol abuse, renal disease, abnormal renal and hepatic function, staying at a nursing home, simultaneous intake of more than five other drugs (Supplemental Table 3), indicators (yes/no) of aspirin, clopidogrel, non-steroidal anti-inflammatory, antidepressant, antibiotic and antiarrhythmic drugs. The PS matching was evaluated by standardized distances between the matched groups and judged to be nonequivalent if the difference was greater than 0.25 standard deviations.

Cox proportional hazard models adjusted for CHA2DS2VASc and HAS-BLED scores were used to calculate hazard ratios (HR) with $95 \%$ confidence intervals (CI) corresponding to a 5\% significance level with days since index date as time-scale. The assumption of proportional hazards was tested through an interaction term between the logarithm of time to the event and the exposure. All analyses were performed with SAS ${ }^{\circledR}$ Enterprise Guide, Version 7.1 (SAS Institute Inc., Cary, NC, USA)

\section{Ethical Approval}

The current research was performed by employees at the Swedish National Board of Health and Welfare (NBHW) in collaboration with employees at Karolinska Institutet. NBHW is a government agency and may, in accordance with Swedish law, use population-based registers to follow and analyze health and social conditions among the population without the requirement of ethical permission.

\section{Results}

The eligible population comprised 4,384 first time DTI users, 21,944 first time VKA users and 19,349 first time Xabans users. The matched study populations consisted of 7,264 patients for the DTIs vs VKAs comparison, 12,566 patients for the Xabans vs VKAs comparison and 6,606 patients for the Xabans vs DTIs comparison (Figure 1), in total 26,436 patients. 


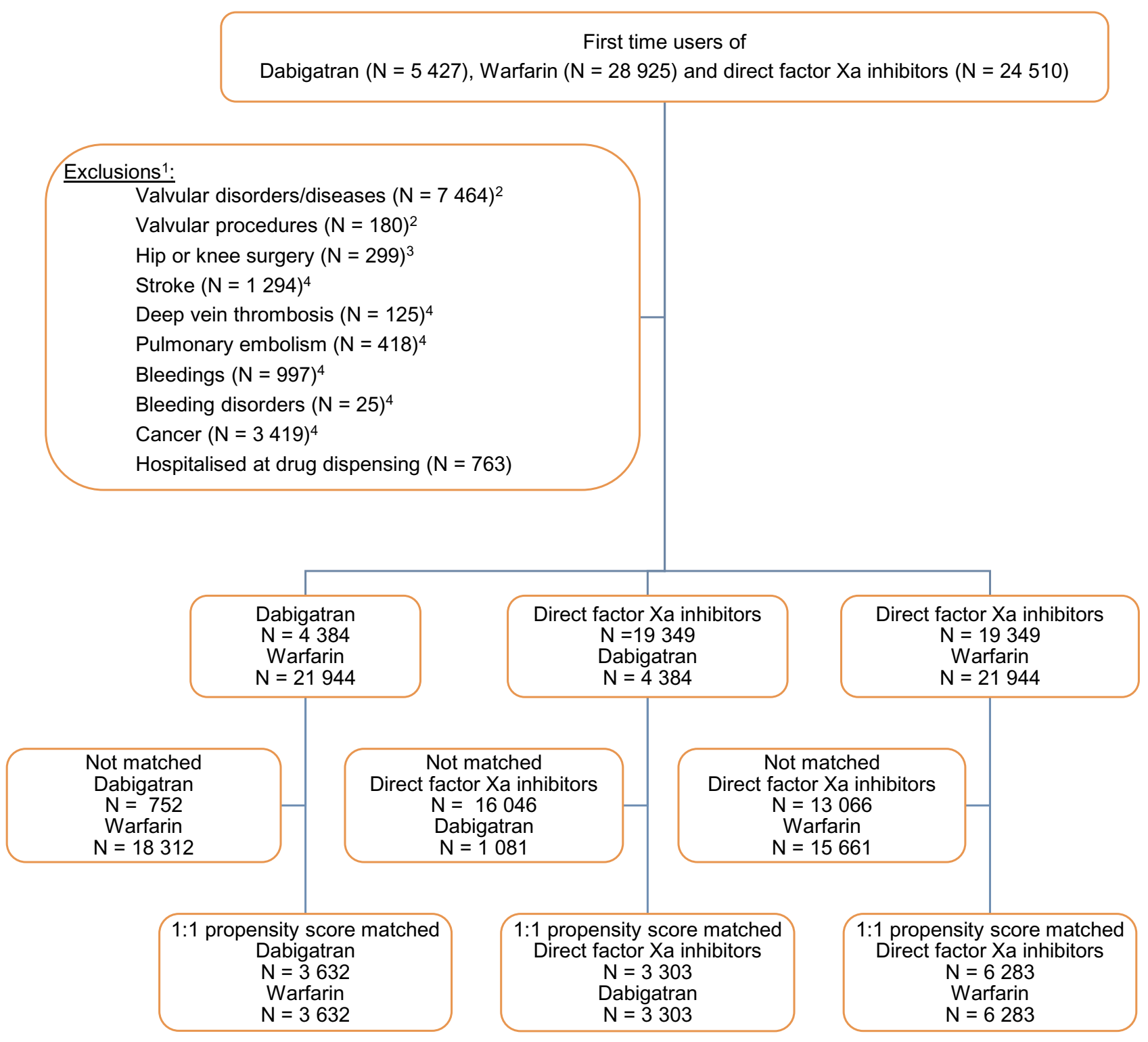

Figure I Flow chart of the study population. All patients were 60 years of age or older and with a diagnosis of atrial fibrillation within 6 months before start of treatment with dabigatran, direct factor $\mathrm{Xa}$ inhibitors or with warfarin.

Notes: 'Individuals could fulfil more than one exclusion criteria. ${ }^{2}$ To include only non-valvular atrial fibrillation, excluding valvular atrial fibrillation. ${ }^{3}$ To exclude thrombosis prophylaxis after elective knee/hip joint replacements, look-back period is 5 weeks. ${ }^{4}$ To exclude patients at altered risk for the outcomes, look-back period is 6 months.

\section{Characteristics of the Study Populations}

Table 1 presents the baseline characteristics of first-time users of DTIs, Xabans and VKAs. Standardized differences are presented in Supplemental Table 5.

\section{Analytical results}

We analyzed one primary and three secondary outcomes, each for DTIs vs VKAs, Xabans vs DTIs and Xabans vs VKAs. The main analysis was subgrouped by sex and age category simultaneously, Table 2. Additional analyses were subgrouped by sex, age category or user status (naïve, experienced), Supplemental Tables 6-8. All results are given as HRs with $95 \%$ CIs. Only results from the main analysis for comparisons with VKAs are listed as text.

\section{Gastrointestinal Bleeding}

In general, the numerically highest HRs were observed for women in the age categories; $75-80,80-85$ and above 85 years of age. In particular, for DTIs vs VKAs, the numerically highest HRs were seen for women in the age groups below 75, 75-80 and 80-85; 1.97 (0.90, 4.60), 2.29 (0.67, $10.40)$ and $6.00(1.02,113.47)$, respectively. Conversely, 
Table I Baseline Characteristics for All Included, Matched Individuals by Propensity Score Matched Cohorts and Index Drug. All Patients Were 60 Years of Age or Older and with a Diagnosis of Atrial Fibrillation Within 6 Months Before Start of Treatment with Direct Thrombin Inhibitors, Direct Factor Xa Inhibitors or with Vitamin K Antagonists

\begin{tabular}{|c|c|c|c|c|c|c|}
\hline \multirow[t]{2}{*}{ Characteristics } & \multicolumn{2}{|c|}{$\begin{array}{l}\text { Direct Thrombin } \\
\text { Inhibitors vs Vitamin } \\
\text { K Antagonists }\end{array}$} & \multicolumn{2}{|c|}{$\begin{array}{l}\text { Direct Factor Xa } \\
\text { Inhibitors vs Direct } \\
\text { Thrombin Inhibitors }\end{array}$} & \multicolumn{2}{|c|}{$\begin{array}{l}\text { Direct Factor } \mathrm{Xa} \\
\text { Inhibitors vs Vitamin } \\
\text { K Antagonists }\end{array}$} \\
\hline & DTI & VKA & XAB & DTI & XAB & VKA \\
\hline Total, n & 3632 & 3632 & 3303 & 3303 & 6283 & 6283 \\
\hline Age, mean (SD) & $72.8(7.7)$ & 73.1 (7.8) & $73.0(7.7)$ & $72.7(7.7)$ & $75.6(8.5)$ & $75.6(8.3)$ \\
\hline Female, n (\%) & 1705 (46.9\%) & $17 \mid 4(47.2 \%)$ & 1545 (46.8\%) & 1557 (47.1\%) & $3120(49.7 \%)$ & $3125(49.7 \%)$ \\
\hline CHA2DS2VASc, ${ }^{a}$ mean (SD) & $3.0(1.5)$ & $3.0(1.5)$ & $2.9(1.5)$ & $2.9(1.5)$ & $3.4(1.6)$ & $3.4(1.6)$ \\
\hline Modified HAS-BLED, ${ }^{\mathrm{b}}$ mean (SD) & $2.2(1.0)$ & $2.2(1.0)$ & $2.1(1.0)$ & $2.1(1.0)$ & $2.4(1.1)$ & $2.4(\mathrm{I} . \mathrm{I})$ \\
\hline Hospitalization (days), mean (SD) & $0.9(3.1)$ & $0.9(3.3)$ & $0.9(2.9)$ & $0.9(3.1)$ & $1.4(4.0)$ & $1.4(4.0)$ \\
\hline Municipal services (hours), mean (SD) & $1.3(10.2)$ & I.I (9.2) & I.I (8.6) & $1.4(10.1)$ & $2.6(14.5)$ & $2.7(14.9)$ \\
\hline Number of simultaneous drugs, mean (SD) & $5.3(2.9)$ & $5.4(3.0)$ & $5.2(2.9)$ & $5.3(2.9)$ & $5.9(3.1)$ & $6.0(3.2)$ \\
\hline Number of visits in specialized care, mean (SD) & $1.3(2.0)$ & $1.3(2.0)$ & I.I (I.9) & I.I (I.9) & $1.0(1.9)$ & $1.0(1.9)$ \\
\hline Private clinic, n (\%) & $100(2.8 \%)$ & $93(2.6 \%)$ & $|3|(4.0 \%)$ & $126(3.8 \%)$ & $64(1.0 \%)$ & $58(0.9 \%)$ \\
\hline Urban living, n (\%) & $1818(50.1 \%)$ & $1819(50.1 \%)$ & $1602(48.5 \%)$ & $1620(49.0 \%)$ & $2906(46.3 \%)$ & $2830(45.0 \%)$ \\
\hline \multicolumn{7}{|l|}{ Education } \\
\hline 9-year compulsory, n (\%) & $1134(31.2 \%)$ & $|I| 2 \mid(30.9 \%)$ & 967 (29.3\%) & $996(30.2 \%)$ & $2379(37.9 \%)$ & $2362(37.6 \%)$ \\
\hline High school, n (\%) & $|36|(37.5 \%)$ & $1393(38.4 \%)$ & $1272(38.5 \%)$ & $1255(38.0 \%)$ & $2492(39.7 \%)$ & $2440(38.8 \%)$ \\
\hline Tertiary education, $\mathrm{n}(\%)$ & $1092(30.1 \%)$ & 1067 (29.4\%) & $1019(30.9 \%)$ & $1015(30.7 \%)$ & $|34|(2 \mid .3 \%)$ & $1396(22.2 \%)$ \\
\hline Missing, n (\%) & $45(1.2 \%)$ & $51(1.4 \%)$ & $45(1.4 \%)$ & $37(1.1 \%)$ & $71(1.1 \%)$ & $85(1.4 \%)$ \\
\hline \multicolumn{7}{|l|}{ Comorbidities } \\
\hline Abnormal renal function, $\mathrm{n}(\%)$ & 68 (1.9\%) & $63(1.7 \%)$ & $45(1.4 \%)$ & 55 (1.7\%) & 344 (5.5\%) & 328 (5.2\%) \\
\hline Abnormal hepatic function, $\mathrm{n}(\%)$ & $6(0.2 \%)$ & $7(0.2 \%)$ & $7(0.2 \%)$ & $6(0.2 \%)$ & $23(0.4 \%)$ & $16(0.3 \%)$ \\
\hline Alcohol intake, n (\%) & 121 (3.3\%) & $125(3.4 \%)$ & $105(3.2 \%)$ & $104(3.1 \%)$ & $170(2.7 \%)$ & $158(2.5 \%)$ \\
\hline Bleedings, n (\%) & $446(12.3 \%)$ & $45 \mathrm{I}(12.4 \%)$ & $434(13.1 \%)$ & $418(12.7 \%)$ & 938 (14.9\%) & 948 (15.1\%) \\
\hline Congestive heart failure, $\mathrm{n}(\%)$ & 755 (20.8\%) & $763(21.0 \%)$ & $629(19.0 \%)$ & $638(19.3 \%)$ & 1697 (27.0\%) & $1667(26.5 \%)$ \\
\hline Diabetes, n (\%) & $496(13.7 \%)$ & 485 (13.4\%) & $423(12.8 \%)$ & 427 (12.9\%) & $1023(16.3 \%)$ & $1015(16.2 \%)$ \\
\hline Disorders of thyroid gland, $\mathrm{n}(\%)$ & $330(9.1 \%)$ & $330(9.1 \%)$ & $288(8.7 \%)$ & $299(9.1 \%)$ & $597(9.5 \%)$ & $590(9.4 \%)$ \\
\hline Embolism, n (\%) & $27(0.7 \%)$ & $32(0.9 \%)$ & $23(0.7 \%)$ & $25(0.8 \%)$ & $64(1.0 \%)$ & $61(1.0 \%)$ \\
\hline Hepatic disease, n (\%) & 61 (1.7\%) & $6 \mathrm{I}(1.7 \%)$ & $50(1.5 \%)$ & $51(1.5 \%)$ & $124(2.0 \%)$ & $107(1.7 \%)$ \\
\hline Hypertension, n (\%) & $2409(66.3 \%)$ & $2428(66.9 \%)$ & $2108(63.8 \%)$ & $2132(64.5 \%)$ & 4483 (7I. $4 \%)$ & $4498(71.6 \%)$ \\
\hline Ischemic stroke, n (\%) & $15 \mathrm{I}(4.2 \%)$ & 137 (3.8\%) & 129 (3.9\%) & 133 (4.0\%) & $328(5.2 \%)$ & $317(5.0 \%)$ \\
\hline Peripheral arterial disease, $\mathrm{n}$ (\%) & $132(3.6 \%)$ & $14 \mid(3.9 \%)$ & $126(3.8 \%)$ & $110(3.3 \%)$ & 328 (5.2\%) & $324(5.2 \%)$ \\
\hline Renal disease, n (\%) & $64(1.8 \%)$ & $56(1.5 \%)$ & $40(1.2 \%)$ & $49(1.5 \%)$ & $328(5.2 \%)$ & $313(5.0 \%)$ \\
\hline Transient ischemic attack, n (\%) & $160(4.4 \%)$ & $163(4.5 \%)$ & 137 (4.1\%) & 142 (4.3\%) & $335(5.3 \%)$ & $343(5.5 \%)$ \\
\hline Vascular disease, n (\%) & 317 (8.7\%) & $323(8.9 \%)$ & 289 (8.7\%) & $282(8.5 \%)$ & $817(13.0 \%)$ & $810(12.9 \%)$ \\
\hline \multicolumn{7}{|l|}{ Comedication } \\
\hline Antiarrhythmics, n (\%) & $84(2.3 \%)$ & 87 (2.4\%) & $64(1.9 \%)$ & $59(1.8 \%)$ & $189(3.0 \%)$ & $212(3.4 \%)$ \\
\hline Antibiotics, n (\%) & $\mathrm{I}(0.0 \%)$ & $2(0.1 \%)$ & $0(0.0 \%)$ & $\mathrm{I}(0.0 \%)$ & $\mathrm{I}(0.0 \%)$ & $2(0.0 \%)$ \\
\hline Antidepressants, n (\%) & $194(5.3 \%)$ & $204(5.6 \%)$ & $186(5.6 \%)$ & $180(5.4 \%)$ & $396(6.3 \%)$ & $385(6.1 \%)$ \\
\hline Antimycotics, n (\%) & I $(0.0 \%)$ & $0(0.0 \%)$ & $0(0.0 \%)$ & I (0.0\%) & I $(0.0 \%)$ & $0(0.0 \%)$ \\
\hline Low dose acetylsalicylic acid, n (\%) & $1243(34.2 \%)$ & 1257 (34.6\%) & 1005 (30.4\%) & $998(30.2 \%)$ & $2232(35.5 \%)$ & $2223(35.4 \%)$ \\
\hline Clopidogrel, n (\%) & 110 (3.0\%) & $103(2.8 \%)$ & $95(2.9 \%)$ & $89(2.7 \%)$ & $28 \mathrm{I}(4.5 \%)$ & $287(4.6 \%)$ \\
\hline NSAIDs, ${ }^{c}$ n (\%) & $204(5.6 \%)$ & $194(5.3 \%)$ & $180(5.4 \%)$ & $185(5.6 \%)$ & $302(4.8 \%)$ & 301 (4.8\%) \\
\hline Other previous anticoagulants, $\mathrm{n}(\%)$ & 1725 (47.5\%) & $1749(48.2 \%)$ & 1470 (44.5\%) & $1444(43.7 \%)$ & $3252(51.8 \%)$ & $3283(52.3 \%)$ \\
\hline Steroids, n (\%) & 142 (3.9\%) & 144 (4.0\%) & $|4|(4.3 \%)$ & $124(3.8 \%)$ & $304(4.8 \%)$ & $311(4.9 \%)$ \\
\hline
\end{tabular}

Notes: a'Score based on congestive heart failure, hypertension, age, diabetes, stroke, vascular disease and sex. 'bcore based on hypertension, abnormal renal function, abnormal hepatic function, stroke, bleedings, age, medicines and alcohol intake. ${ }^{\mathrm{C}}$ Anti-inflammatory and antirheumatic products, non-steroids.

Abbreviations: DTI, direct thrombin inhibitors; VKA, vitamin $\mathrm{K}$ antagonists; $\mathrm{XAB}$, direct factor $\mathrm{Xa}$ inhibitors. 


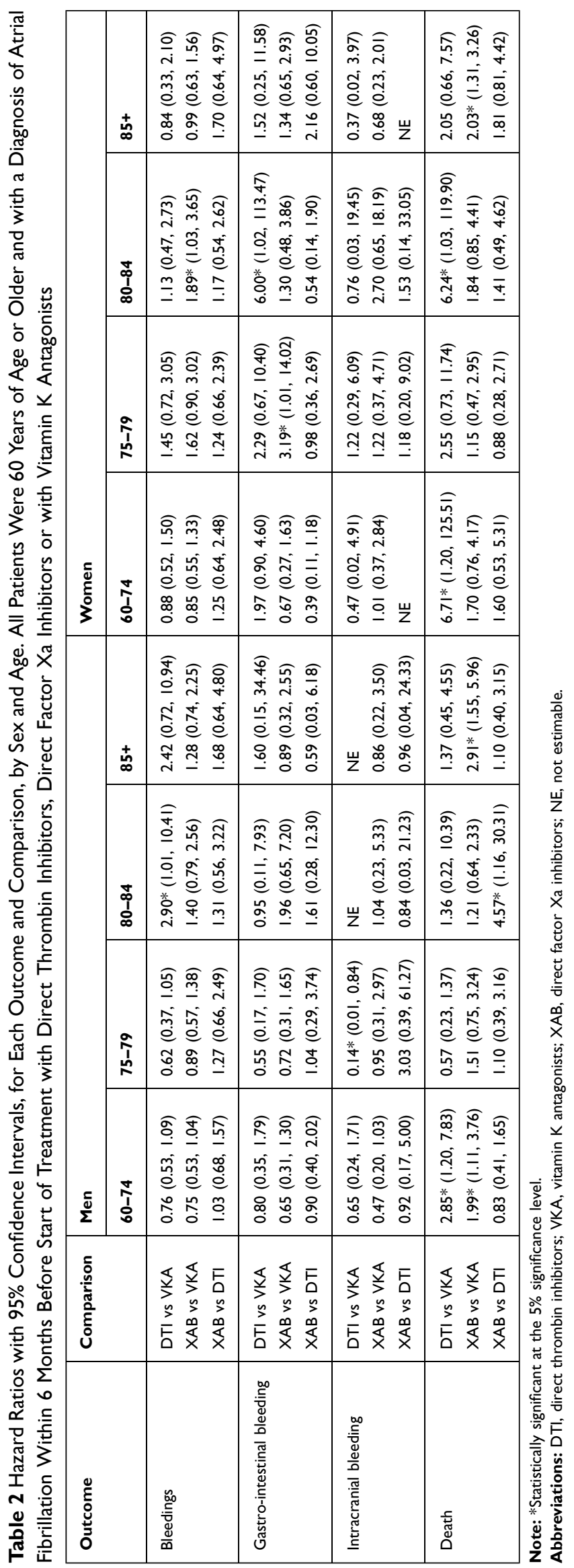


the numerically lowest HR was observed for men 75-80 years, $0.55(0.17,1.70)$. For Xabans vs VKAs, the numerically highest HRs were observed for women 75-80 years and for men 80-85 years; 3.19 (1.01, 14.02) and 1.96 $(0.65,7.20)$, respectively. The numerically lowest HR $0.65(0.31,1.30)$ was seen for men $60-75$ years.

\section{Any Bleeding}

In general, the numerically highest HRs were observed in the highest age groups $80-85$ and above 85 years for both sexes. In particular, for DTIs vs VKAs, the numerically highest HRs were observed for men in the age groups 80 85 and above 85 years; $2.90(1.01,10.41)$ and $2.42(0.72$, 10.94), respectively. Conversely, the numerically lowest HR $0.62(0.37,1.05)$ was seen for men $75-80$ years. For Xabans vs VKAs, the numerically highest HRs were observed for women in the age groups 75-80 and 80-85, $1.62(0.90,3.02)$ and $1.89(1.03,3.65)$, respectively.

\section{Intracranial Bleeding}

In general, the numerically highest HRs were observed for women in the higher age categories; 75-80 and 80-85 years of age. In particular, for DTIs vs VKAs, a numerically low HR $0.14(0.01,0.84)$ was observed for men $75-$ 80 years of age. For Xabans vs VKAs, a numerically high HR 2.70 (0.65, 18.19) was observed for women 80-85 years and a numerically low $\operatorname{HR} 0.47(0.20,1.03)$ for men 60-75 years.

\section{Mortality}

For mortality, no general pattern was observed. In particular, for DTIs vs VKAs, numerically high, but imprecise, HRs were seen for women $60-75$ and $80-85$ years of age; $6.71(1.20,125.51)$ and $6.24(1.03,119.90)$, respectively. Also, a numerically low $\operatorname{HR} 0.57$ (0.23, 1.37) was observed for men 75-80 years. For Xabans vs VKAs, a numerically high HR $2.91(1.55,5.96)$ was observed for men above 85 years.

\section{Discussion}

Even though there are a plethora of studies on DOACs already published, few comprise large, Nordic, unselected populations of patients with $\mathrm{AF}$ from nationwide registers including all available DOACs simultaneously to compare bleeding outcomes between each DOAC class and VKAs, additionally describing sex and age differences. In this observational nationwide register study, we found the following statistically significant associations of increased risk at the $5 \%$ level when comparing DTIs or Xabans with VKAs: gastrointestinal bleeding in women, overall and in age groups 75-80 and 80-85; any bleeding in both men and women 80-85 years of age, and also overall for the age group 80-85 years; all-cause mortality in both sexes, across different age groups and for both naive and experienced users. However, part of the risks may be attributed to the patient characteristics and could be a consequence of confounding by indication. ${ }^{21}$ The differences between the reported results in this and previous studies may also lie in different methodological approaches.

Case reports have raised awareness about the risk of gastrointestinal bleedings associated with dabigatran. ${ }^{6,8,22}$ For apixaban and rivaroxaban, there are less reports on gastrointestinal bleedings. ${ }^{23,24}$ A meta-analysis including 43 randomized controlled trials showed an increased risk for gastrointestinal bleedings in patients treated with new oral anticoagulants for venous thromboembolism or acute coronary syndrome. ${ }^{25}$ A French nationwide propensity matched cohort study showed no difference in bleeding or other outcomes between VKAs and DOACs, suggesting equal caution to be exercised by physicians in both groups. ${ }^{12}$ However, a retrospective study of commercially insured people in the US found no significant risk for gastrointestinal bleedings when comparing dabigatran or rivaroxaban with warfarin. They noted that the excess risk of gastrointestinal bleedings with dabigatran relative to warfarin reported in other studies may be age dependent and concentrated among the oldest, a population that was not well represented in their study. ${ }^{10}$ Similarly, a retrospective propensity matched study based on administrative claims data in the US showed similar gastrointestinal bleeding risks in dabigatran or rivaroxaban and warfarin. ${ }^{26}$ A Danish study, with a similar design to ours, showed no risk of gastrointestinal bleedings associated with low- or high-dose dabigatran use. ${ }^{11}$ This could be due to differing administrations of DOACs or due to the underreporting of adverse events of the new oral anticoagulants, though a third Danish nationwide cohort study described that oral anticoagulant naïve dabigatran users initiated proton pump inhibitors more often than those treated with warfarin. ${ }^{27}$ A Food and Drug Administration study of Medicare beneficiaries found an increased risk of gastrointestinal bleedings in new users of dabigatran compared to warfarin in elderly patients with nonvalvular atrial fibrillation. ${ }^{7}$ The present study found more than two-fold risks for gastrointestinal bleedings associated with DTIs or Xabans as compared to VKAs among female patients aged $75-80$ or $80-85$ years with AF. Graham et al also reported a two-fold increased risk of gastrointestinal 
bleedings in women aged 85 years and older. ${ }^{7}$ A metaanalysis including eight studies comprising 9,417 patients concluded that women suffer more bleeding complications compared to men when using a DOAC for venous thromboembolism. ${ }^{28}$ This indicates that greater attention should be given in DOAC treated women with nonvalvular AF.

The present study could not find any elevated bleeding risk with respect to user status (naïve or experienced). A short-term observational Danish study among patients with $\mathrm{AF}$ indicated an association between bleeding risk and VKA experience status for the $110 \mathrm{mg}$ dose of dabigatran. ${ }^{29}$ A sub-study of the RE-LY trial found no difference in bleeding risk when comparing VKA-experienced with VKA-naïve users. ${ }^{30}$ Nevertheless, another Danish register study showed an increased risk of gastrointestinal bleedings among VKA initiators of warfarin, but no excess risk of bleedings when comparing dabigatran to warfarin users irrespective of VKA experience. ${ }^{31}$

Nathan et al performed reviews of case reports of bleeding events involving dabigatran, Xabans and warfarin in the food and drug administration adverse event reporting system and found a signal between DOAC use and life-threatening or serious bleeding. ${ }^{32}$ The present study found a more than two-fold risk of any bleeding for men $80-85$ or 85 and above years of age.

Eikelboom et al found that dabigatran compared to warfarin had lower risks of intracranial bleeding. ${ }^{33}$ In our study, we found a protective effect of dabigatran over warfarin for men 75-80 years of age. On the other hand, we found a more than two-fold risk of intracranial bleeding associated with Xabans as compared to VKAs in women $80-85$ years of age.

The Medicare study noted a significant $87 \%$ risk of allcause mortality in patients more than or equal to 75 years in association with dabigatran use. In a large meta-analysis, the new oral anticoagulants were significantly associated with a lower risk of mortality. ${ }^{34}$ The current study found excess risks of mortality for both DTIs and Xabans as compared to VKAs in both sexes and varying age groups.

The current study used nationwide data from wellcharacterized registers precluding recall bias. It only included first-time users of DTIs, Xabans or VKAs, given the potential risk of channeling toward DTIs or Xabans due to previous compliance problems or adverse effects with VKAs. We compared DTIs and Xaban users separately and did not combine the two classes since they might have different risk profiles. The use of propensity scores enabled well-balanced comparison groups.

This was a real-world study using national registers; therefore, residual confounding cannot be ruled out. There is no information available in the national registers on time in therapeutic range (TTR) for warfarin users. Lack of knowledge on TTR precludes analyses of good and poorly controlled warfarin users and their bleeding risk. It has been shown that high values of TTR correlate with a reduction in complications such as bleeding and thrombosis. ${ }^{35}$ However, it has been reported that TTR of warfarin users in Sweden is high (mean value $76.2 \%$ ) compared to TTR in some clinical trials. ${ }^{13,35,36}$ We did not have access to the prescribed dose and prescriptions may be guided by the patients bleeding risk and hence other doses than the recommended may be used as presented in a French study. ${ }^{12}$ The definition of diseases relied on ICD-10 codes from hospital care and since some diseases are diagnosed in primary care (not included in NPR) the study might have missed milder cases of AF. However, it has been shown that only $12 \%$ of the AF diagnoses in Stockholm county council (2006-2010) are covered exclusively by primary care, ie $88 \%$ of the diagnoses were captured. ${ }^{37}$ For hypertension, it has been shown that the specificity defined through the prescription of at least two classes of antihypertensive drugs was almost $95 \%{ }^{38}$ The CHA2DS2VASc and HAS-BLED scores were based on recorded diagnoses and may be underestimated. However, this approach has been used successfully in previous studies and was adopted for comparative reasons. ${ }^{11,27,31,39}$ We investigated the objectives in an incident cohort and have not estimated risks in switchers, also we compared only drug classes, not specific drugs. The study did not have information on some lifestyle factors related to the outcomes, such as body mass index, smoking, physical activity, hemoglobin levels and alcohol consumption. Lastly, the present results are based on filled prescriptions assuming adherence.

\section{Conclusion}

The results are consistent with previous studies showing an increased risk in mainly gastrointestinal bleedings in first-time users of DTIs and Xabans. The risks of all-cause mortality merit further studies and a special attention from care-providers to vulnerable groups.

\section{Acknowledgments}

An earlier version of this manuscript was presented at the ISPE in Boston 2015. We would like to thank Gudrun Jonasdottir Bergman for statistical help. 


\section{Author Contributions}

All authors contributed to data analysis, drafting or revising the article, have agreed on the journal to which the article will be submitted, gave final approval of the version to be published, and agree to be accountable for all aspects of the work.

\section{Disclosure}

ML and HK are employed at the Centre for Pharmacoepidemiology, which receive grants from several entities (pharmaceutical companies, regulatory authorities and contract research organizations) for the performance of drug safety and drug utilization studies. The authors report no other conflicts of interest in this work.

\section{References}

1. Friberg L. Atrial fibrillation prevalence revisited. J Intern Med. 2013;274(5):461-468. doi:10.1111/joim.12114

2. Lindberg T, Wimo A, Elmståhl S, Qiu C, Bohman DM, Sanmartin Berglund J. Prevalence and Incidence of Atrial Fibrillation and Other Arrhythmias in the General Older Population: Findings From the Swedish National Study on Aging and Care. Gerontol Geriatr Med. 2019;5:2333721419859687. Published 2019 Jun 27. doi:10.1177/ 2333721419859687

3. Reddy P, Atay JK, Selbovitz LG, et al. Dabigatran: a review of clinical and pharmacoeconomic evidence. Crit Pathw Cardiol. 2011;10(3):117-127. doi:10.1097/HPC.0b013e3182315c03

4. Byon W, Garonzik S, Boyd RA, et al. Apixaban: a clinical pharmacokinetic and pharmacodynamic review. Clin Pharmacokinet. 2019;58(10):1265-1279. doi:10.1007/s40262-019-00775-Z

5. Kvasnicka T, Malikova I, Zenahlikova Z, et al. Rivaroxaban - metabolism, pharmacologic properties and drug interactions. Curr Drug Metab. 2017;18(7):636-642. doi:10.2174/1389200218666170518165443

6. Chen BC, Viny AD, Garlich FM, et al. Hemorrhagic complications associated with dabigatran use. Clin Toxicol. 2012;50(9):854-857. doi:10.3109/15563650.2012.721888

7. Graham DJ, Reichman ME, Wernecke M, et al. Cardiovascular, bleeding, and mortality risks in elderly Medicare patients treated with dabigatran or warfarin for nonvalvular atrial fibrillation. Circulation. 2015;131(2):157-164. doi:10.1161/CIRCULATIONAHA.114.012061

8. Hernandez I, Baik SH, Piñera A, et al. Risk of bleeding with dabigatran in atrial fibrillation. JAMA Intern Med. 2015;175(1):18-24. doi:10.1001/jamainternmed.2014.5398

9. Wychowski MK, Kouides PA, et al. Dabigatran-induced gastrointestinal bleeding in an elderly patient with moderate renal impairment. Ann Pharmacother. 2012;46(4):608. doi:10.1345/aph.1Q747

10. Chang HY, Zhou M, Tang W, et al. Risk of gastrointestinal bleeding associated with oral anticoagulants: population based retrospective cohort study. Br Med J. 2015;350(h1585):1-7. doi:10.1136/bmj.h1585

11. Larsen TB, Rasmussen LH, Skjøth F, et al. Efficacy and safety of dabigatran etexilate and warfarin in "real-world" patients with atrial fibrillation: a prospective nationwide cohort study. J Am Coll Cardiol. 2013;61(22):2264-2273. doi:10.1016/j.jacc.2013.03.020

12. Maura G, Blotière P-O, Bouillon K, et al. Comparison of the short-term risk of bleeding and arterial thromboembolic events in nonvalvular atrial fibrillation patients newly treated with dabigatran or rivaroxaban versus vitamin $\mathrm{K}$ antagonists: a French nationwide propensity-matched cohort study. Circulation. 2015;132 (13):1252-1260. doi:10.1161/CIRCULATIONAHA.115.015710
13. Connolly SJ, Ezekowitz MD, Yusuf S, Investigators RLSCa, et al. Dabigatran versus warfarin in patients with atrial fibrillation. $N$ Engl J Med. 2009;361(12):1139-1151. doi:10.1056/NEJMoa0 905561.

14. Granger CB, Alexander JH, McMurray JJV, et al. Apixaban versus warfarin in patients with atrial fibrillation. $N$ Engl J Med. 2011;365 (11):981-992. doi:10.1056/NEJMoa1107039

15. Patel MR, Mahaffey KW, Garg J, Investigators. RA, et al. Rivaroxaban versus warfarin in nonvalvular atrial fibrillation. $N$ Engl $\mathrm{J} \mathrm{Med}$. 2011;365(10):883-891. doi:10.1056/NEJMoa1009638.

16. Ludvigsson JF, Otterblad-Olausson P, Pettersson BU, et al. The Swedish personal identity number: possibilities and pitfalls in healthcare and medical research. Eur J Epidemiol. 2009;24(11):659-667. doi:10.1007/s10654-009-9350-y

17. Ludvigsson JF, Andersson E, Ekbom A, et al. External review and validation of the Swedish national inpatient register. BMC Public Health. 2011;11(1):1-16. doi:10.1186/1471-2458-11-450

18. Wettermark B, Hammar N, MichaelFored C, et al. The new Swedish Prescribed Drug Register-opportunities for pharmacoepidemiological research and experience from the first six months. Pharmacoepidemiol Drug Saf. 2007;16(7):726-735. doi:10.1002/pds.1294

19. WHO Collaborating Centre for Drug Statistics Methodology ON. DDD: definition and general considerations. Available from: https:// www.whocc.no/ddd/definition_and_general_considera/. Accessed February 26, 2020.

20. Reducing PL Bias in a Propensity Score Matched-Pair Sample Using Greedy Matching Techniques. Paper presented at: Twenty-Sixth Annual SAS Users Group International Conference, 2001; Long Beach, California.

21. Signorello LB, McLaughlin JK, Lipworth L, et al. Confounding by indication in epidemiologic studies of commonly used analgesics. Am J Ther. 2002;9(3):199-205. doi:10.1097/00045391-20020500000005

22. Southworth MR, Reichman ME, Unger EF, et al. Dabigatran and postmarketing reports of bleeding. $N$ Engl J Med. 2013;368 (14):1272-1274. doi:10.1056/NEJMp1302834

23. Yen HW. Fatal nonvariceal gastrointestinal bleeding in a cirrhotic patient taking apixaban with no history of hemorrhage. Cureus. 2019;11(11):e6126.

24. Lakatos B, et al. Gastrointestinal bleeding associated with rivaroxaban administration in a treated patient infected with human immunodeficiency virus. Swiss Med Wkly. 2014;144:w13906.

25. Holster IL, Valkhoff VE, Kuipers EJ, et al. New oral anticoagulants increase risk for gastrointestinal bleeding: a systematic review and meta-analysis. Gastroenterology. 2013;145(1):105-112. doi:10.1053/ j.gastro.2013.02.041

26. Abraham NS, Singh S, Alexander GC, et al. Comparative risk of gastrointestinal bleeding with dabigatran, rivaroxaban, and warfarin: population based cohort study. Br Med J. 2015;350(h1857):1-9. doi:10.1136/bmj.h1857

27. Staerk L, Gislason GH, Lip GYH, et al. Risk of gastrointestinal adverse effects of dabigatran compared with warfarin among patients with atrial fibrillation: a nationwide cohort study. Europace. 2015;17 (8):1215-1222. doi:10.1093/europace/euv119

28. Alotaibi GS, Almodaimegh H, McMurtry MS, et al. Do women bleed more than men when prescribed novel oral anticoagulants for venous thromboembolism? A sex-based meta-analysis. Thromb Res. 2013;132(2):185-189. doi:10.1016/j.thromres.2013.07.017

29. Sørensen R, Gislason G, Torp-Pedersen C, et al. Dabigatran use in Danish atrial fibrillation patients in 2011: a nationwide study. BMJ Open. 2013;3(5):1-9. doi:10.1136/bmjopen-2013-002758

30. Ezekowitz MD, Wallentin L, Connolly SJ, Investigators RLSCa, et al. Dabigatran and warfarin in vitamin $\mathrm{K}$ antagonist-naive and -experienced cohorts with atrial fibrillation. Circulation. 2010;122(22):2246-2253. doi:10.1161/CIRCULATIONAHA.110. 973735 . 
31. Larsen TB, Gorst-Rasmussen A, Rasmussen LH, et al. Bleeding events among new starters and switchers to dabigatran compared with warfarin in atrial fibrillation. Am J Med. 2014;127(7):650-656. doi:10.1016/j.amjmed.2014.01.031

32. Nathan KT, Conn KM, van Manen RP, et al. Signal detection for bleeding associated with the use of direct oral anticoagulants. Am J Health Syst Pharm. 2018;75(13):973-977. doi:10.2146/ajhp170529

33. Eikelboom JW, Wallentin L, Connolly SJ, et al. Risk of bleeding with 2 doses of dabigatran compared with warfarin in older and younger patients with atrial fibrillation: an analysis of the randomized evaluation of long-term anticoagulant therapy (RE-LY) trial. Circulation. 2011;123 (21):2363-2372. doi:10.1161/CIRCULATIONAHA.110.004747

34. Capodanno D, Capranzano P, Giacchi G, et al. Novel oral anticoagulants versus warfarin in non-valvular atrial fibrillation: a meta-analysis of 50,578 patients. Int $J$ Cardiol. 2013;167 (4):1237-1241. doi:10.1016/j.ijcard.2012.03.148

35. Wieloch M, Sjalander A, Frykman V, et al. Anticoagulation control in Sweden: reports of time in therapeutic range, major bleeding, and thrombo-embolic complications from the national quality registry AuriculA. Eur Heart J. 2011;32(18):2282-2290. doi:10.1093/eurheartj/ehr134
36. Singer DE, Hellkamp AS, Piccini JP, et al. Impact of global geographic region on time in therapeutic range on warfarin anticoagulant therapy: data from the ROCKET AF clinical trial. $J$ Am Heart Assoc. 2013;2(1):e000067. doi:10.1161/JAHA.112.000067

37. Forslund T, Wettermark B, Wändell P, et al. Risk scoring and thromboprophylactic treatment of patients with atrial fibrillation with and without access to primary healthcare data: experience from the Stockholm health care system. Int J Cardiol. 2013;170(2):208-214. doi:10.1016/j.ijcard.2013.10.063

38. Olesen JB, Lip GYH, Hansen ML, et al. Validation of risk stratification schemes for predicting stroke and thromboembolism in patients with atrial fibrillation: nationwide cohort study. BMJ. 2011;342(jan31 1):1-9. doi:10.1136/bmj.d124

39. Larsen TB, Rasmussen LH, Gorst-Rasmussen A, et al. Dabigatran and warfarin for secondary prevention of stroke in atrial fibrillation patients: a nationwide cohort study. Am J Med. 2014;127(12):1172-8. e5. doi:10.1016/j.amjmed.2014.07.023
Clinical Epidemiology

\section{Publish your work in this journal}

Clinical Epidemiology is an international, peer-reviewed, open access, online journal focusing on disease and drug epidemiology, identification of risk factors and screening procedures to develop optimal preventative initiatives and programs. Specific topics include: diagnosis, prognosis, treatment, screening, prevention, risk factor modification, systematic reviews, risk \& safety of medical interventions, epidemiology \& biostatistical methods, and evaluation of guidelines, translational medicine, health policies \& economic evaluations. The manuscript management system is completely online and includes a very quick and fair peer-review system, which is all easy to use. 